Article

\title{
Assessment of the Release of Vascular Endothelial Growth Factor from 3D-Printed Poly- $\varepsilon$-Caprolactone/Hydroxyapatite/Calcium Sulfate Scaffold with Enhanced Osteogenic Capacity
}

\author{
Cheng-Yu Chen ${ }^{1,+}$, Chien-Chang Chen ${ }^{2}$, Chen-Ying Wang ${ }^{1,3,+} \mathbb{\oplus}$, Alvin Kai-Xing Lee ${ }^{2,4}$, \\ Chun-Liang Yeh ${ }^{1}$ (D) and Chun-Pin Lin ${ }^{1,5, *}$ \\ 1 Graduate Institute of Clinical Dentistry, School of Dentistry, National Taiwan University, \\ Taipei 10617, Taiwan; k55599911@gmail.com (C.-Y.C.); jybean@gmail.com (C.-Y.W.); \\ staryeh0524@gmail.com (C.-L.Y.) \\ 2 3D Printing Medical Research Center, China Medical University Hospital, China Medical University, \\ Taichung 40447, Taiwan; m0975371198@gmail.com (C.-C.C.); Leekaixingalvin@gmail.com (A.K.-X.L.) \\ 3 Section of Periodontics, Department of Dentistry, National Taiwan University Hospital, Taipei 10617, Taiwan \\ 4 School of Medicine, China Medical University, Taichung 40447, Taiwan \\ 5 Department of Dentistry, National Taiwan University Hospital, Taipei 10617, Taiwan \\ * Correspondence: pinlin@ntu.edu.tw; Tel.: +886-2-2312-3456 (ext. 67335) \\ + Both authors contributed equally to this work.
}

Received: 5 June 2020; Accepted: 23 June 2020; Published: 29 June 2020

check for updates

\begin{abstract}
Vascular endothelial growth factor (VEGF) is one of the most crucial growth factors and an assistant for the adjustment of bone regeneration. In this study, a 3D scaffold is fabricated using the method of fused deposition modeling. Such a fabricated method allows us to fabricate scaffolds with consistent pore sizes, which could promote cellular ingrowth into scaffolds. Therefore, we drafted a plan to accelerate bone regeneration via VEGF released from the hydroxyapatite/calcium sulfate (HACS) scaffold. Herein, HACS will gradually degrade and provide a suitable environment for cell growth and differentiation. In addition, HACS scaffolds have higher mechanical properties and drug release compared with HA scaffolds. The drug release profile of the VEGF-loaded scaffolds showed that VEGF could be loaded and released in a stable manner. Furthermore, initial results showed that VEGF-loaded scaffolds could significantly enhance the proliferation of human mesenchymal stem cells (hMSCs) and human umbilical vein endothelial cells (HUVEC). In addition, angiogenic- and osteogenic-related proteins were substantially increased in the HACS/VEGF group. Moreover, in vivo results revealed that HACS/VEGF improved the regeneration of the rabbit's femur bone defect, and VEGF loading improved bone tissue regeneration and remineralization after implantation for 8 weeks. All these results strongly imply that the strategy of VEGF loading onto scaffolds could be a potential candidate for future bone tissue engineering.
\end{abstract}

Keywords: vascular endothelial growth factor; 3D printing; porous scaffold; hydroxyapatite; calcium sulfate; bone regeneration

\section{Introduction}

Bone defects due to trauma, disease or congenital origins are common but they represent a very sophisticated disorder in our current generation which is affecting millions of people worldwide [1]. The most common causes of bone defects are trauma, tumor and iatrogenic wound infections. Furthermore, with an increasingly aging population, cases of bone defects due to chronic degenerative 
diseases, such as osteoporosis, osteoarthritis and even hyperparathyroidism, have increased gradually over the years. Current treatment options, regardless of medical or surgical methods, are severely limited by local problems such as abnormal fibrosis and lack of vascularization. The latest gold standard for treating bone defects is bone grafting and various types of grafts exist to serve this purpose, including the traditional methods of autograft, allograft and xenograft, as well as the newer method of artificial bioceramics [2]. It is common knowledge that strategies such as allografts or xenografts have lower success rates and much higher rates of rejection as such grafts are of foreign origin and thus can cause serious tissue inflammation, which would eventually lead to tissue failure. Therefore, autografts remain the most widely accepted treatment method for bone defects. However, problems such as a lack of harvesting sites and the need to undergo multiple surgical procedures and risks severely limit the application of autografting in clinical applications. In addition, chronic degenerative diseases are usually systemic, and, thus, in such patients, we are unable to harvest bones from another autologous site. Furthermore, autografts are also greatly limited by the size of the bone defect. Therefore, there is a need to understand the mechanisms of bone regeneration and formation in order to overcome these problems and make a breakthrough [3].

Bioceramics is a common material used for bone and dental applications such as periodontal repair, mandibular reconstruction and even for the fabrication of artificial joints [4]. There are several types of biomaterials, such as hydroxyapatite (HA), calcium sulfate (CS) and calcium silicate, which are commonly used due to their high biocompatibility, bioactivity and low cytotoxicity [4]. In addition, it was also reported that their structures are able to mimic native bones and can effectively help bone repair. For instance, the microstructure of bioceramics allow it to have the ability to promote ossification and neovascularization, and such abilities are critical for osteoinduction, osteoconduction and osseointegration [5]. In recent years, bioceramics combined with three-dimensional (3D) printing is starting to become a popular trend due to its excellent customization, biocompatibility and bioactivity [6]. Such 3D printing technology has been widely applied to bone tissue engineering as it gives us the flexibility to customize personalized grafts according to one's need quickly and with reproducibility [7-9]. Certain parameters are known to be characteristics and properties of scaffolds, such as porosity, pore size and shape, sinter temperature, crystal distribution and phase composition [10-12]. It is worth noting that porosity is a critical factor and a uniform porosity was shown to allow good bio-resorption, biodegradation and a stable release rate of ions, thus leading to subsequently enhanced bone regeneration, bone remodeling, angiogenesis and vascularization [13]. The application of 3D printing in medicine thus allows us to fabricate scaffolds with tunable structural characteristics in order to overcome clinical problems [14-16]. Recent studies have shown that the modification of bioceramics with natural materials can enhance the biocompatibility and bioactivity of bioceramics, thus making it a better potential candidate as compared to pure bioceramics $[17,18]$. Several studies have indicated that modification with HA bioceramics composites was able to improve the material's physicochemical properties, enhancing its mechanical properties and accelerating cellular proliferation and differentiation, thus leading to the promotion of osteoconduction [19-21]. HA is a type of calcium phosphate which is known to be the most stable amongst the various calcium phosphates. Its precipitation can form high-density crystallization, with a Ca/P ratio of 1.67. [22]. However, there were no significant results from these initial studies as HA was directly applied to bone defects and live tissues. This occurred during the later stages, when studies began mixing HA into synthesizable materials and fabricating them into scaffolds. Such studies showed enhanced osteogenesis and osteoinduction capabilities, thus laying a foundation for future bone tissue engineering research [23]. On the other hand, calcium sulfate (CS) is also a type of calcium phosphate which is widely used in bone repair and remodeling due to its excellent biodegradability and setting time [24]. Recent novel studies inspired by mussels have shown that growth factors can be attached to scaffolds via a simple immersion technique [15]. Many studies have since then attempted to modify the surface of bioceramic scaffolds in order to enhance the bioactivity of scaffolds [25]. In the previous study, we developed 
HACS bioceramics with the sustained release of growth factors and this demonstrated a high potential to promote hard tissue regeneration [26].

Vascular endothelial growth factor (also called VEGF-A or VEGF) and its corresponding receptor (VEGFR) have been shown to mediate physiological reactions such as angiogenesis and bone development and they even play a role cancer development [27]. VEGF is a homodimer glycoprotein which belongs to a family of multipotent cytokines including VEGF-A, VEGF-B, VEGF-C, VEGF-D and PIGF. VEGF was originally observed as a growth factor which showed the behaviors of increased vascular permeability and endothelial cell migration and proliferation, which have well-known effects on angiogenic differentiation [28]. Moreover, VEGF was reported to be the most important growth factor in vessel development [7]. It is common knowledge that angiogenesis is essential for the regulation of many physiological functions and even for bone regeneration and ossification [29]. In the process of bone regeneration, VEGF plays a vital role in promoting osteoblast formation and mineralization at the site of the bone defect [30]. In addition, osteoblasts are known to secrete VEGF-A, which has been shown to promote osteoprogenitor cell differentiation and also enhance the secretion of bone-related cytokines such as collagen, Runx2, transforming growth factor (TGF) and alkaline phosphatase (ALP) which allow for increased extracellular matrix (ECM) and bone matrix remodeling [31]. Numerous studies have attempted to combine various types of bioceramics with HA and it has been widely reported that such combinations have several limitations, such as unstable degradation, thus leading to hydroxyapatite agglomeration issues.

Therefore, in this study, our hypothesis was that a combination with CS would make up for the limitations of HA by stabilizing degradation rates and release rates, and thus we attempted to fabricate a hybrid mesoporous bioceramic material made out of HA, CS, and polycaprolactone (PCL). Our study used 3D printing to fabricate porous scaffolds made up of HACS, which was then modified with a VEGF coating. It was shown that these scaffolds were not only able to enhance angiogenesis but also stimulate bone regeneration by enhancing cell proliferation, differentiation and cytokine secretion. This article provides a novel insight into bone tissue engineering by showing the synchronous cooperation of VEGF with bioceramics.

\section{Results and Discussion}

\subsection{The Characterization of HACS Scaffold}

Recently, 3D printing has emerged as a suitable and potential technique to fabricate personalized scaffolds for various clinical conditions. Both hydroxyapatite (HA) and calcium sulfate (CS) are known to be materials with excellent levels of biocompatibility and are widely used in tissue engineering as bone graft substitutes and even as drug carrier devices [32]. HA and CS have been investigated in both in vitro and in vivo studies and initial results have revealed that both HA and CS were able to enhance bone regeneration [33]. Photo images of the scaffolds were taken, and these are shown in Figure $1 \mathrm{~A}$. As seen, the scaffold was a $6 \mathrm{~mm} \times 6 \mathrm{~mm} \times 10 \mathrm{~mm}$ rectangle and the distance between each layer was $400 \mu \mathrm{m}$ (Figure 1B). In addition, each strut and pore were uniform and the shearing tears were neat at each end of the strut. The XRD distribution of each type of scaffold is shown in Figure 1 C,D. The strongest diffraction peaks of the HACS scaffolds were found at $2 \theta=26^{\circ}, 29^{\circ}$ and $32.5^{\circ}$, thus indicating that the crystalline hydroxyapatite was present in the scaffolds. In our previous study, we demonstrated that HA-based scaffolds had peaks at $2 \theta=26^{\circ}, 29^{\circ}$ and $32.5^{\circ}$, further confirming the presence of HA in our present scaffold [24]. Furthermore, we also showed that HA-based scaffolds had high biocompatibility and that the pores that were well-interconnected were able to enhance bone and tissue regeneration [34]. In recent years, there have been increasing reports and evidence showing that scaffolds with uniform pores and rough surfaces had enhanced cellular proliferation and differentiation as compared to scaffolds with flat surfaces and no pores [35]. Furthermore, Huang et al. reported that a 3D-printed mesoporous calcium silicate scaffold could enhance the strength and biocompatibility of scaffolds, thus making it more suitable for bone tissue engineering [36]. Similarly, our previous studies 
demonstrated that porous scaffolds with good connectivity and permeability were able to enhance dental pulp cell proliferation and attachment [36]. In this study, we successfully fabricated porous HACS scaffolds using 3D printing. Results showed that HA was presented in our scaffolds and that scaffolds could be fabricated with the desired structural uniformity and characteristics. Therefore, in consultation with the results from our previous studies and by others, we hypothesized that our HACS scaffold could enhance cellular activities and subsequently enhance bone regeneration as desired.
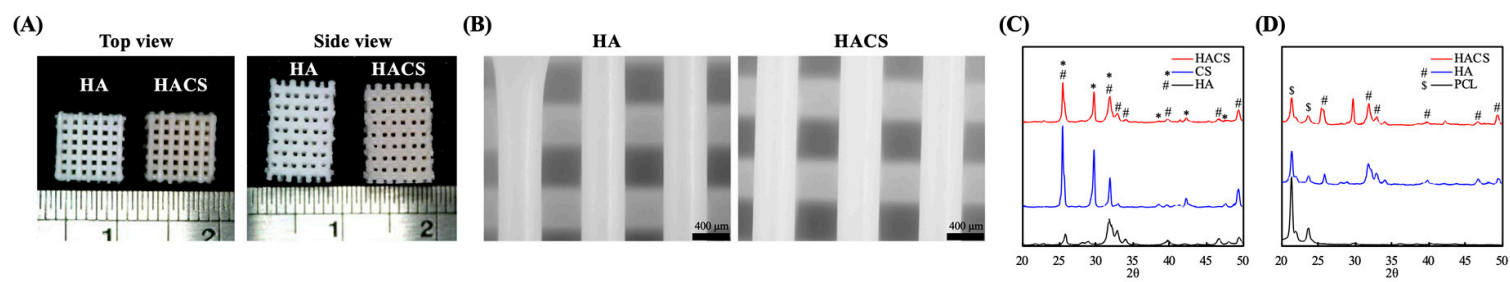

Figure 1. The photographs of (A) different view, (B) high magnification and (C) X-ray diffraction patterns of the hydroxyapatite (HA), calcium sulfate (CS) and HACS powder and (D) the 3D printed HA, HACS and PCL scaffolds.

\subsection{Properties of Immersed Scaffolds}

The degradation and the mechanical properties of scaffolds have also been demonstrated as a crucial index for bone and vascular tissue regeneration [35]. The weight loss profile of HACS and HA scaffolds after simulated body fluid (SBF) immersion were determined at different time periods and the results are shown in Figure 2. The weight of the HACS scaffold was reduced gradually during the duration of the soaking, with a $17.44 \%$ and $26.34 \%$ weight loss at 1 and 3 months, respectively. The HACS scaffold lost a total of $39.70 \%$ after 6 months, which was 2.27 -fold more than the first month. However, the HA scaffold had just $11.75 \%$ of weight loss after 6 months of immersion. This result demonstrated that the HACS scaffold had a faster biodegradation rate as compared to the HA scaffold, thus making it a better candidate for bone tissue engineering, as bone tends to take up to 6 months to heal completely. Scaffolds for bone tissue engineering need to be of a certain mechanical strength as the scaffolds need to withstand a harsh compressive environment after implantation. Figure 3 shows the typical stress-strain curves of the HACS and HA scaffolds at 1 and 6 months. The HACS scaffold was seen to be able to withstand up to approximately 7.06 MPa of stress in its initial stages, which increased to $17 \mathrm{MPa}$ after 1 month. However, the HA scaffolds were only able to withstand up to $5.49 \mathrm{MPa}$ of stress at the initial stage and $9.97 \mathrm{MPa}$ at 1 month. After 6 months of immersion, both the HACS and HA scaffolds had a significant decrease in their mechanical strength, with HACS having 7.2 MPa and HA having 4.9 MPa. Through these results, it can be seen that HACS had better mechanical properties than the HA group, thus making it a better candidate for future bone engineering applications. Furthermore, previous studies have showed a correlation between the degradation and mechanical properties of scaffolds and the biological functions of cells [37]. It was concluded that scaffolds with controllable degradation and better mechanical properties were able to enhance proliferation, vascularization and regeneration. Therefore, it was hypothesized that HACS scaffolds would perform better in enhancing cellular activities as compared to HA scaffolds. 


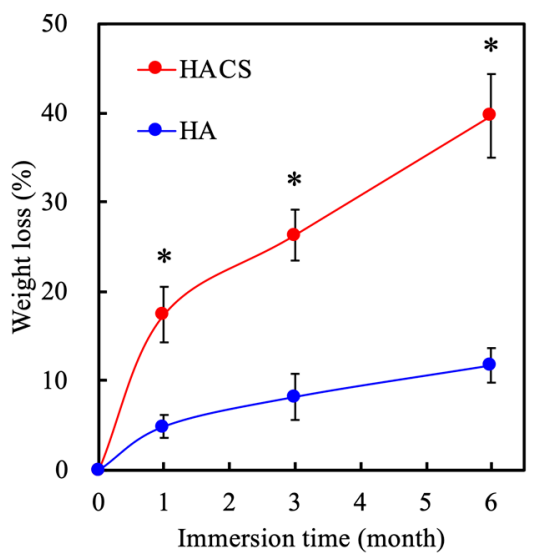

Figure 2. The degradation profile of HA and HACS scaffolds after being immersed in SBF for 6 months. Data are presented as mean $\pm \mathrm{SEM}, n=6$ for each group. ${ }^{*} p<0.05$ compared with HA.

Scaffold

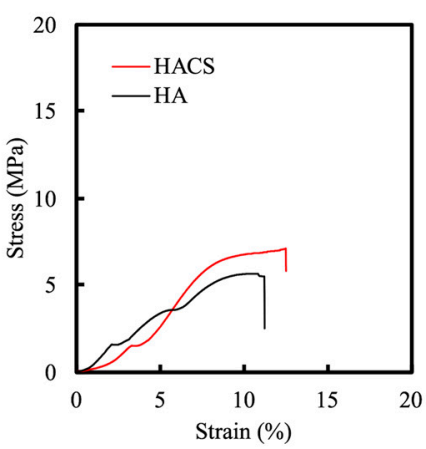

1 month

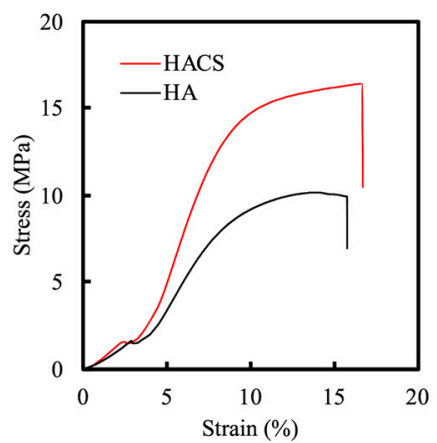

6 month

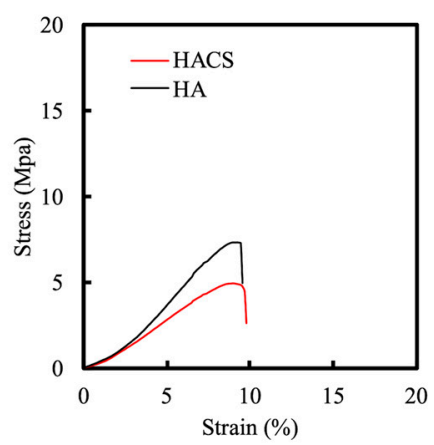

Figure 3. Stress-strain curves of HA and HACS scaffolds before and after immersion in SBF for 1 month and 6 months.

\subsection{VEGF Release}

HACS scaffolds had a higher degradation rate as compared to HA scaffolds, thus making them better candidates for the loading of drugs or growth factors to allow for sustained release over a period of time [38]. Figure 4 shows the cumulative amount of VEGF released from drug-loaded HACS scaffolds in order to assess for their angiogenesis ability. At 1 and 14 days of immersion, the amount of VEGF released from the HACS scaffold was $1.42 \mu \mathrm{g} / \mathrm{mL}$ and $3.04 \mu \mathrm{g} / \mathrm{mL}$, respectively. Furthermore, it was noted that the VEGF increased in a time-dependent manner over the period of immersion. Recent studies have attempted to load growth factor onto scaffolds so as to enhance wound healing or tissue regeneration $[39,40]$. According to Li et al., a VEGF-loaded hydroxyapatite-collagen scaffold was able to enhance angiogenesis and osteogenesis in an ischemic limb rat model [31]. Our results revealed that HACS scaffolds had the capability to release VEGF in a time-dependent manner, suggesting that the HACS scaffolds were able to induce neovascularization and thus play a vital role in bone tissue regeneration. In addition, it was hypothesized that the plateau of release from the HA scaffold was due to the slower degradation of HA as compared to HACS. Other reports have been made confirming that drug release could be affected by the rate of degradation. A study by Yusop et al. showed that curcumin release was affected by the addition of iron to scaffolds; as such, a modification was able to enhance the degradation of poly(lactic-co-glycolic acid) scaffolds [41]. 


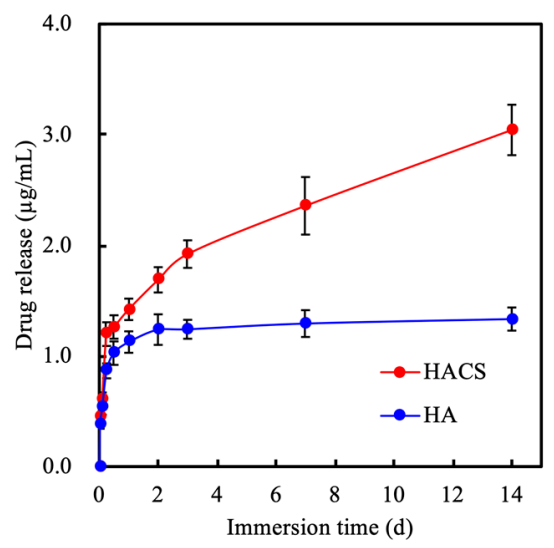

Figure 4. Vascular endothelial growth factor (VEGF) release from HA and HACS scaffolds after immersion in the cultured medium at $37^{\circ} \mathrm{C}$ for 14 days.

\subsection{Cell Proliferation}

VEGF was reported to be able to modulate cell function, which includes proliferation, migration and differentiation [42]. For this study, HA and HACS scaffolds were immersed in VEGF solution $(0.5 \mu \mathrm{g} / \mathrm{mL})$ for $12 \mathrm{~h}$ to allow for VEGF loading. In addition, the cells were incubated onto the scaffolds for different time intervals. At all time-points, the HACS/VEGF scaffolds had a significantly higher proliferation $(p<0.05)$ of human mesenchymal stem cells (hMSCs) (Figure 5A) and human umbilical vein endothelial cells (HUVECs) (Figure 5B) as compared to the other groups. It was hypothesized that HACS scaffolds were able to release growth factor in a stable manner, thus enhancing cellular growth and proliferation. The VEGF family constitutes the largest sub-group of the growth factor family that was found to play a role in bone development, regeneration and remodeling [43]. Amongst the VEGF family, VEGF-A was the representative for angiogenesis and VEGF-A not only acts as a nutrient for bone cells but also stimulates mineralization and differentiation into osteoblast lineages [44]. Scaffolds carrying VEGF have been shown to promote the secretion of bone-related proteins, such as BMP-2, OPN and OCN, which are all known to be critical components for bone regeneration $[45,46]$. To further observe for cell morphology, scaffolds were seeded with either hMSCs or HUVECs and cultured on scaffolds for 3 days, and the results are shown in Figure 6. Cellular attachment and proliferation were assessed at 3 and 7 days with F-actin and nuclei imaging. As seen, the cells that were cultured on the HACS scaffold were flattened and had more mitotic spindles and fibers as compared to the control groups. This indicated that HACS/VEGF scaffolds were able to provide a better environment for cells, thus allowing cells to have better attachment and proliferation. The staining assay of MSCs and HUVECs was conducted on different days because of the different cell adhesion abilities. In our results, the two kinds of cells were measured on different days because MSCs need more time to adapt to the scaffold. However, the image of this staining demonstrated that the cell proliferation rate was increasingly elevated as each day passed. This suggests that this scaffold had low cytotoxicity and contributed to cell growth and attachment. It was also important to note that the degree of cellular attachment could be used as a reliable predictor for subsequent cellular behaviors. Reports have been made stating that the cells that were better adhered onto the surfaces of scaffolds had significantly higher proliferation and differentiation as compared to cells which had poor adhesion [47]. Similarly, it could be seen that HACS scaffolds had significantly higher proliferation as compared to HA scaffolds. 
(A)

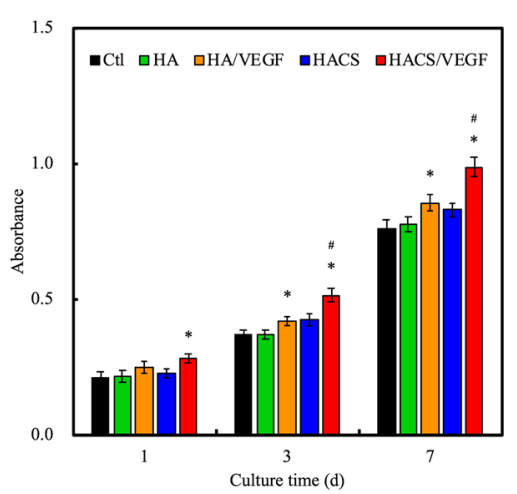

(B)

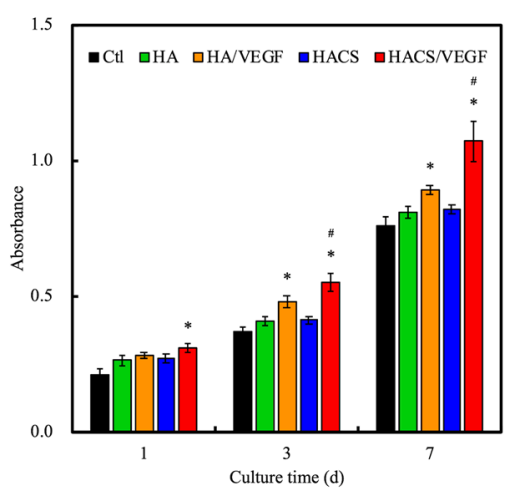

Figure 5. The proliferation of (A) human mesenchymal stem cells (hMSCs) and (B) human umbilical vein endothelial cells (HUVECs) cultured on different 3D-printed scaffolds. "**" indicates a significant difference $(p<0.05)$ when compared to the scaffold without VEGF. "\#" indicates a significant difference $(p<0.05)$ when compared to HA/VEGF.

hMSCs

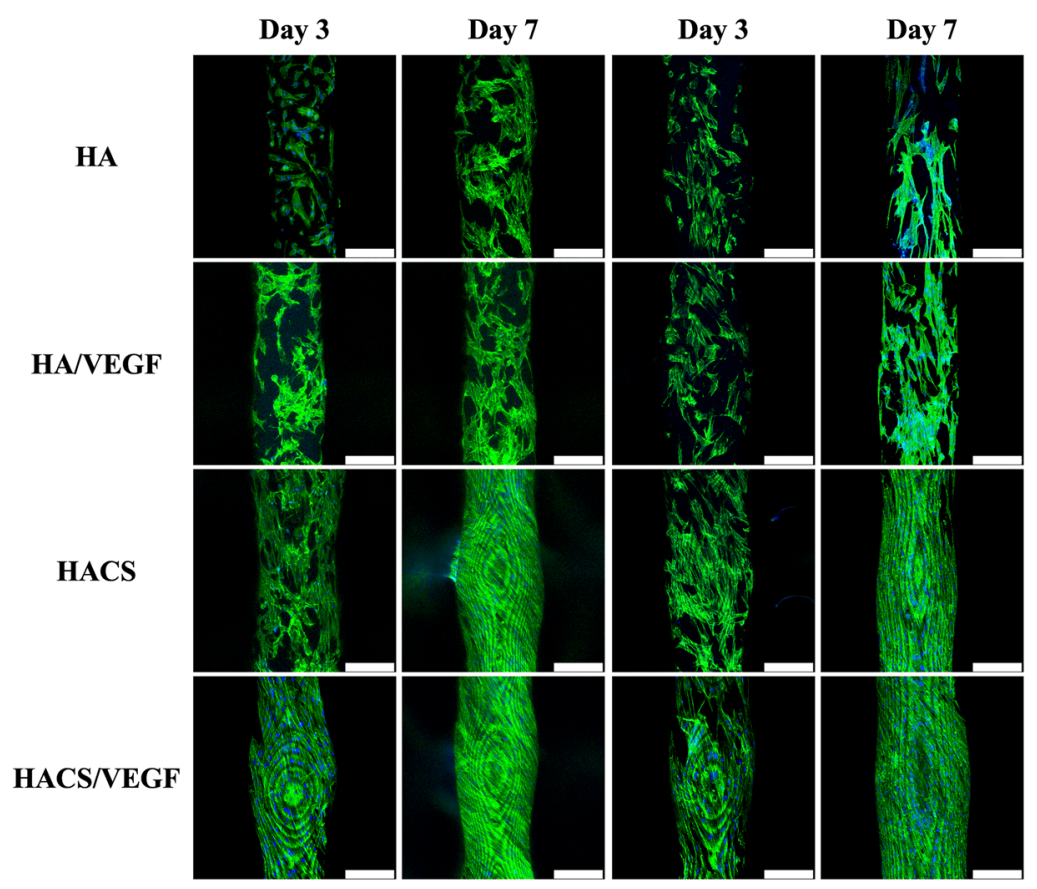

Figure 6. The F-actin filaments (green) and nuclei (blue) staining of hMSCs and HUVECs cultured on the scaffolds for 3 and 7 days. The scale bar is $400 \mu \mathrm{m}$.

\subsection{Angiogenesis}

HUVECs were used in this study to verify the angiogenic capability of the HACS/VEGF scaffolds. As seen in Figure 7, the expression of the von Willebrand factor (vWF) and Angiopoietin-1 (Ang-1) were significantly higher for those cells that were cultured on the HACS/VEGF scaffolds. vWF is a complexed protein which is known to regulate homeostasis, angiogenesis and even blood formation. During tissue damage, $\mathrm{vWF}$ is known to be able to trap platelets and the surface membrane glycoprotein IIb IIIa to accelerate platelets' agglutination. Past studies have pointed out that Ang-1 overexpression can increase bone mass and induce expression of bone formation markers (OCN, BMP2 and Runx2) to accelerate new bone formation [48]. Our results demonstrated that, at all time-points, the HACS/VEGF scaffolds had the highest expression of vWF and Ang-1, with the HACS/VEGF scaffolds being 1.3-fold higher than the HA/VEGF scaffolds and three-fold higher than the control groups. It was 
hypothesized that the increase in activity was due to the stable release of VEGF, thus allowing for enhanced cellular activities [36]. Various studies have demonstrated that VEGF plays a crucial role in mediating angiogenesis, osteogenesis, differentiation, regeneration and bone remodeling [49]. In addition, Choi et al. reported that Ang-1 was critical in the repair of cranial bone defects by activating bone morphogenetic protein 2 and bone-related gene bone sialoprotein, osteocalcin and osterix activity [50]. These results demonstrated that the HACS/VEGF scaffold possesses increased angiogenesis characteristics and is bound to be an indispensable contribution to neovascularization and osteogenesis.

\section{(A)}

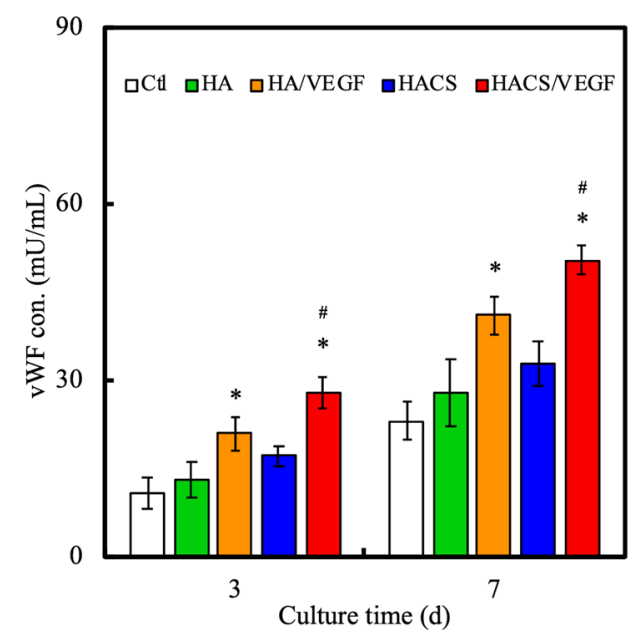

(B)

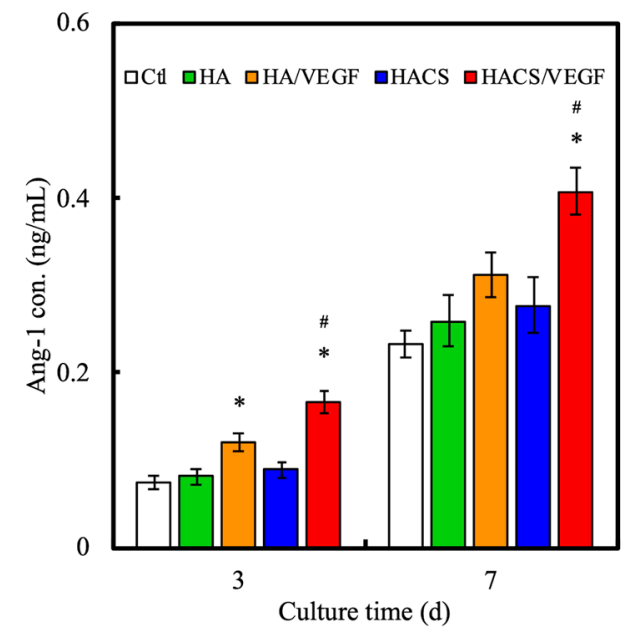

Figure 7. (A) The von Willebrand factor (vWF) and (B) Angiopoietin-1 (Ang-1) protein expression levels of HUVECs cultured on various scaffolds for 3 and 7 days. " "* indicates a significant difference $(p<0.05)$ when compared to the scaffold without VEGF. "\#" indicates a significant difference $(p<0.05)$ when compared to HA/VEGF.

\subsection{Osteogenesis}

Bone-like mineralized nodules are known to be crucial markers for subsequent mineralization and bone tissue formation. In addition, the extent of nodules is also known to modulate osteoblast differentiation [51]. ALP and osteocalcin (OC) were measured to determine the osteogenic capabilities of the HACS/VEGF scaffolds, and the results are shown in Figure 8. As seen, ALP and OC secretion from HACS/VEGF scaffolds increased in a time-dependent manner. According to the previous study, the differentiation behavior of osteogenic cells was significantly enhanced and the osteogenesis-related gene expressions were up-regulated after being cultured on the VEGF-loading scaffold [52]. The alizarin red $S$ assay was used to confirm the extent of mineralization and it can be seen from Figure $8 \mathrm{C}$ that the hMSCs had obviously more mineralization nodules on the HACS/VEGF scaffolds with hMSCs at all time-points as compared to the rest of the groups. After 2 weeks of culture, the nodules on the HACS/VEGF scaffolds were obvious and large enough to be seen with the naked eye. On the other hand, the nodules on the rest of the scaffolds were tiny and sparse. The optical density of alizarin red $\mathrm{S}$ was quantified through the ELISA assay and the quantification results were in good agreement with the results presented above. It was reported that a vascularized scaffold with VEGF had an additive effect on cellular differentiation and proliferation as compared with neat bioceramics materials [53]. Therefore, it is important to verify whether the VEGF-loaded scaffold can accelerate bone tissue regeneration in vivo. 
(A)

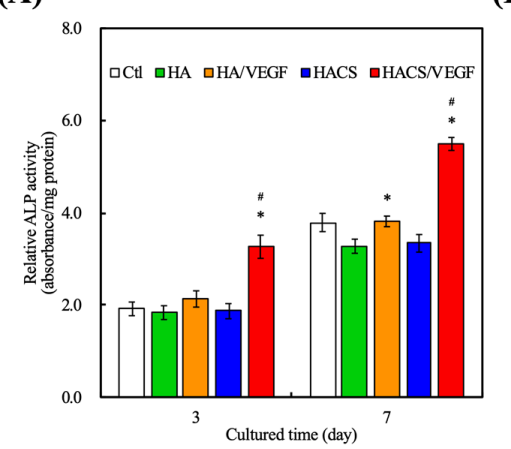

(C)

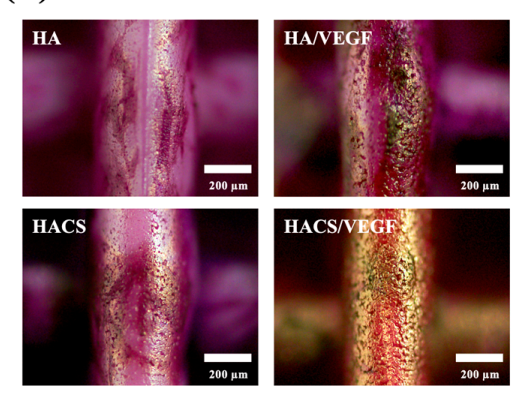

(B)
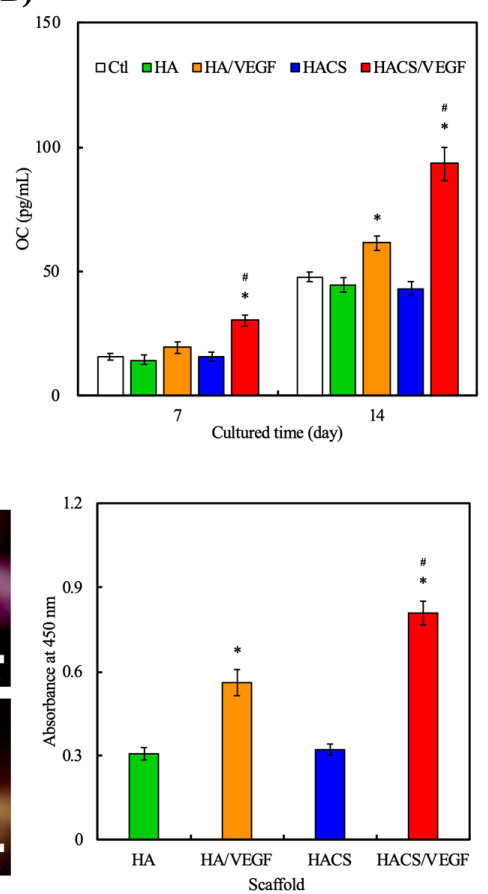

Figure 8. (A) The ALP and (B) OC protein expression levels of hMSCs cultured on various scaffolds for various time-points. (C) Alizarin red S staining and quantification of Ca mineral deposits after culture for 14 days. Data are presented as mean $\pm \mathrm{SEM}, n=3$ for each group. "**" indicates a significant difference $(p<0.05)$ when compared to the scaffold without VEGF. "\#" indicates a significant difference $(p<0.05)$ when compared to HA/VEGF.

\subsection{In Vivo Bone Regeneration}

To investigate the bone regeneration capabilities of the HACS/VEGF scaffolds, we implanted the scaffolds with a diameter of $6 \mathrm{~mm}$ and a height of $6 \mathrm{~mm}$ into the femurs of New Zealand white male rabbits. The in vivo study demonstrated that the HACS scaffolds had greater bone regeneration in the femur defects after implantation for 8 weeks, compared with the HA scaffolds. The $\mu C T$ images (Figure 9A) show that in the HACS scaffold, there was more new bone tissue that could be found and it grew surrounded by the strands of the scaffolds, which served as a template. Moreover, the new bone formation and dense tissue seemed to be obviously improved by the HACS/VEGF scaffold in the defects. The bone volume per tissue volume (BV/TV) ratio of the HACS/VEGF scaffold $(18.7 \% \pm 1.5 \%)$ was significantly higher compared with the HACS $(14.1 \% \pm 0.9 \%)$ and HA scaffolds $(10.7 \% \pm 0.9 \%)$ at 8 weeks, respectively ( $p<0.05$, Figure $9 \mathrm{~B})$. Trabecular thickness (Tb.Th) was significantly higher in HACS/VEGF, compared with those of HA and HACS ( $p<0.05$, Figure 9C). The bone-repairing substitutes played an important role in healing these defects in various cases when body environment provisions were inadequate for self-healing, especially in the 3D scaffold [54]. The regeneration of new bone and the bridging of the defect area with HACS/VEGF scaffolds further verified their biocompatibility and osteogenesis nature.

The scaffold and the surrounding tissues were harvested and treated with hematoxylin (HE), Masson's trichrome (MT) and von Kossa (VK) stains (Figure 10). From the HE staining images, we found that the femur structure and marginal area were the most complete in the HACS/VEGF groups. The MT staining showed the formation of connective tissue, bone collagen and neovascularization in the VEGF-loaded scaffold (Figure 11, red arrows). More newly formed blood vessels could be observed aggregating around the new bone in the HACS/VEGF scaffold. The blood vessels within implants could promote cell proliferation and differentiation that enhance new bone formation and remodeling. In short, the HACS/VEGF scaffolds had better osteoinduction characteristics and these scaffolds were 
better able to enhance bone regeneration and remodeling as compared with the HA, HA/VEGF and HACS scaffolds. Similarly, it was hypothesized that the HACS/VEGF scaffolds would be able to release VEGF steadily, thus providing extra nutrients to bone cells for subsequent cellular activities. The histological results showed that HACS/VEGF scaffolds were better at enhancing bone regeneration and bone formation in vivo as compared to the rest of the groups. Our study provides a novel insight into how HACS/VEGF scaffolds could increase cell proliferation, osteogenesis and angiogenesis and showed that HACS/VEGF has potential in the treatment of bone defects.

(A)

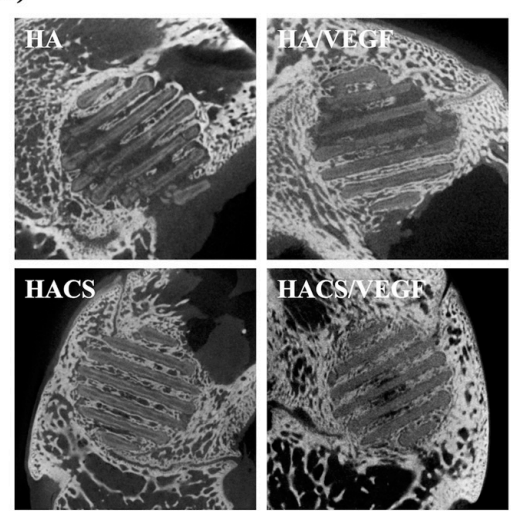

(B)

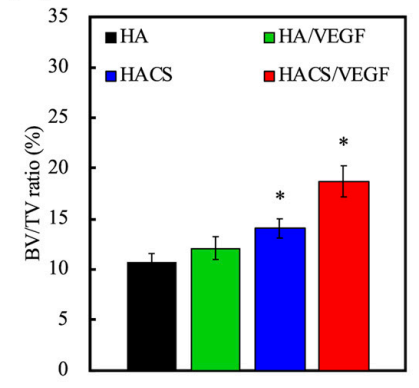

(C)

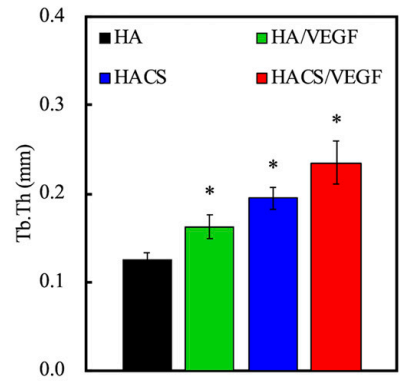

Figure 9. Evaluation of bone formation in vivo. (A) Micro-CT images at week 8. (B) Micro-CT-quantified histograms of $(\mathrm{C})$ bone volume/total volume (BV/TV) and trabecular thickness (Tb.Th). "** indicate a significant difference $(p<0.05)$ when compared to HA.

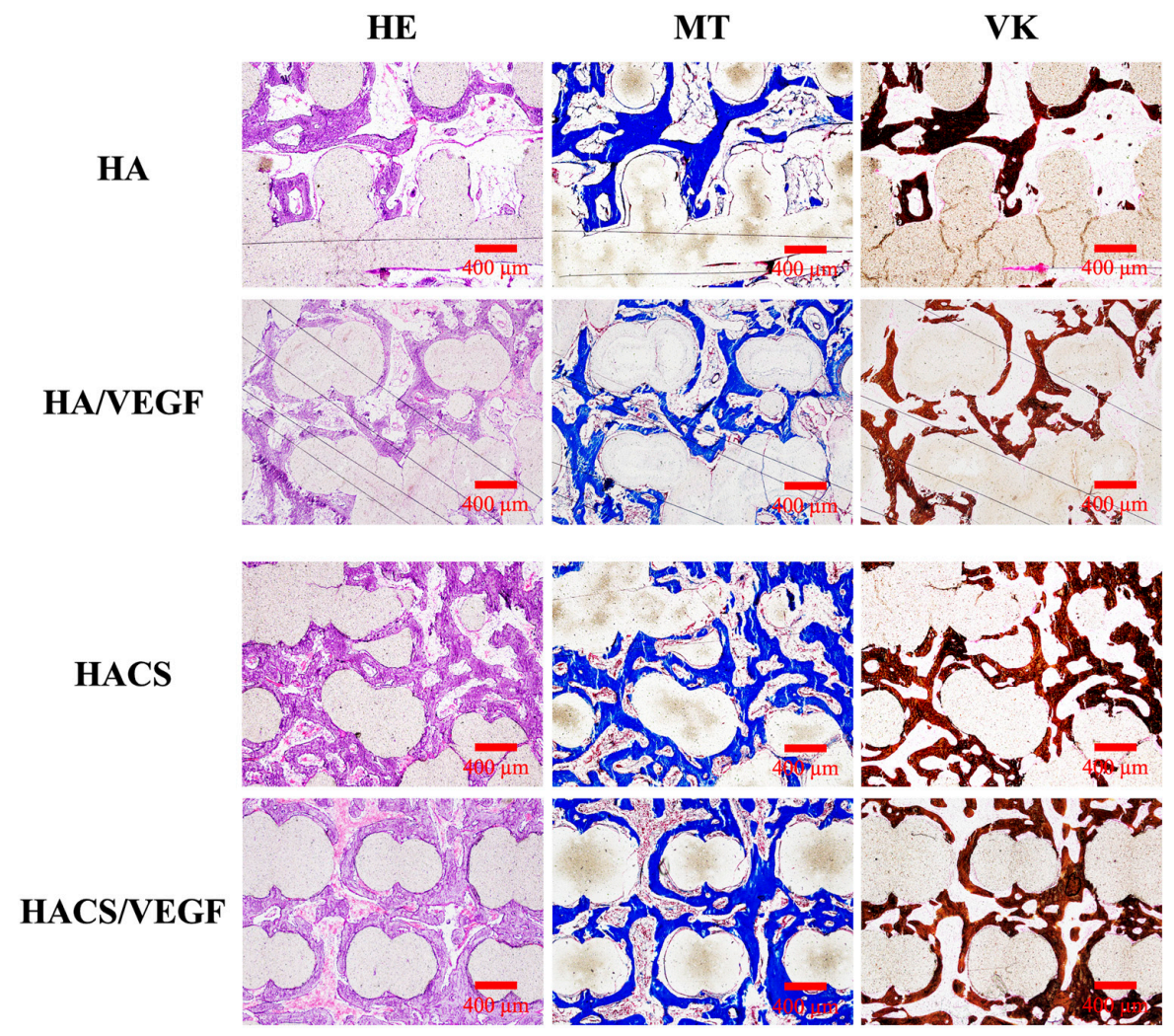

Figure 10. Histological analysis of new bone regeneration around and within the scaffolds in the rabbit femoral defect model. Left: hematoxylin and eosin (HE) stain; middle: Masson's trichrome (MT) stain; right: von Kossa (VK) stain of regenerated bone mass after 8 weeks of regeneration for in vivo experiment. 

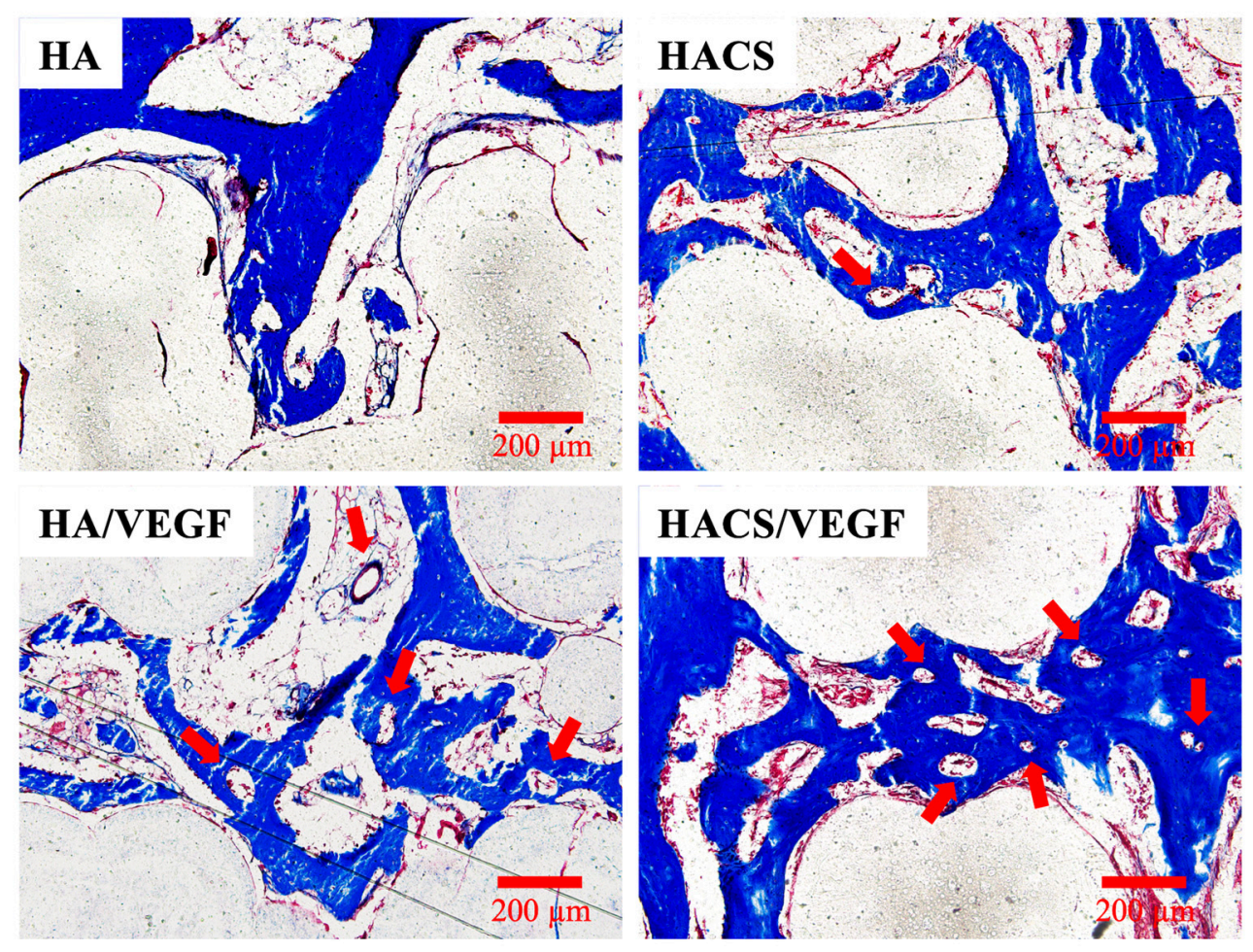

Figure 11. The higher magnification images of MT staining of regenerated bone mass after 8 weeks of regeneration for in vivo experiment. Red arrowheads indicate the blood vessels.

\section{Materials and Methods}

\subsection{Preparation of HACS/PCL Scaffolds}

HA and CS were mixed and milled with a ball in $99 \%$ ethanol in a planetary ball mill (Retsch PM-100, Retsch GmbH, Haan, Germany) for $8 \mathrm{~h}$ and further dried for $12 \mathrm{~h}$ to obtain a raw ceramic powder. X-ray diffraction (XRD; Bruker D8SSS, Karlsruhe, Germany) with a setting of $30 \mathrm{kV}, 30 \mathrm{~mA}$ and a scanning speed of $1 \%$ min was used to characterize the powder materials. Then, PCL (molecular weight of 43,000-50,000; Polysciences, Warrington, PA, USA) was first heated to $100^{\circ} \mathrm{C}$ for $10 \mathrm{~min}$. After this, HACS powder was suspended in absolute alcohol and dripped into the PCL suspension. Finally, the two ratios of HACS/PCL were 50:0:50 and 25:25:50. The mixture was then heated in a $100{ }^{\circ} \mathrm{C}$ oven for $1 \mathrm{~h}$. All scaffolds used in this study were fabricated using 3D printing technology via a 3-axis precision positioning system (Bio-Scaffolder 3.1; GeSiM, Grosserkmannsdorf, Germany). Briefly, the dried mixtures were loaded into syringes and dispensed through the $80{ }^{\circ} \mathrm{C}$ steel nozzle $(400 \mu \mathrm{m})$ with an applied pressure of $200-400 \mathrm{kPa}$ and a printing speed of $1.5-2 \mathrm{~mm} / \mathrm{s}$. The designs of the scaffolds were as follows: seven $500 \mu \mathrm{m}$ parallel struts with a $500 \mu \mathrm{m}$ distance. Then, we used software to quantify the distance between each strut. Each strut had a height of $500 \mu \mathrm{m}$, which was quantified by software, and each layer was printed perpendicular to the layer below. The scaffolds were printed into a $6 \mathrm{~mm} \times 6 \mathrm{~mm} \times 10 \mathrm{~mm}$ rectangle, as described above.

\subsection{In Vitro Soaking}

The scaffolds were immersed in $37{ }^{\circ} \mathrm{C}$ simulated body fluid (SBF) for various durations up to six months. This solution was similar to our native human blood plasma and consisted of $7.9949 \mathrm{~g}$ of $\mathrm{NaCl}$, $0.2235 \mathrm{~g} \mathrm{KCl}, 0.147 \mathrm{~g} \mathrm{~K}_{2} \mathrm{HPO}_{4}, 0.3528 \mathrm{~g} \mathrm{NaHCO}_{3}, 0.071 \mathrm{~g} \mathrm{Na}_{2} \mathrm{SO}_{4}, 0.2775 \mathrm{~g} \mathrm{CaCl}_{2}$ and $0.305 \mathrm{~g} \mathrm{MgCl}_{2}$ mixed with $1000 \mathrm{~mL}$ of distilled $\mathrm{H}_{2} \mathrm{O}$. Hydrochloric acid and tris(hydroxymethyl)aminomethane were used to adjust the $\mathrm{pH}$ of the SBF solution to 7.4. After immersion for various specified durations, the scaffolds were removed from the SBF and weighed on an analytical balance (TE214S, Sartorius, 
Goettingen, Germany) scale. The weight of the scaffolds was recorded to analyze for its in vitro degradation profile. The EZ Test machine (Shimadzu, Kyoto, Japan) was used to determine the mechanical properties of each scaffold at a loading rate of $1 \mathrm{~mm} / \mathrm{min}$. The average values and standard deviations of Young's modulus and the maximal compressive strength were evaluated from the recorded stress-strain curves. Six independent tests were done, and the average was recorded.

\subsection{Cell Culture}

In this study, we used human umbilical vein endothelial cells (HUVECs) and mesenchymal stem cells (hMSCs) which were purchased from Sciencell (Sciencell, Carlsbad, CA, USA) and grown in the commercial cell medium (\#1001 for HUVECs and \#7501 for hMSCs, Sciencell) to passages 3-6, maintained at a $37^{\circ} \mathrm{C}$ humidified atmosphere with $5 \% \mathrm{CO}_{2}$.

\subsection{VEGF Loading}

The scaffolds were immersed in $12.5 \mu \mathrm{g} / \mathrm{mL}$ of VEGF solution (MP Biomedicals, Solon, OH, USA) for the loading of the VEGF [55]. The solution was then placed on an automated shaker for $12 \mathrm{~h}$ at room temperature. After this, the VEGF-loaded scaffolds were rinsed with $\mathrm{ddH}_{2} \mathrm{O}$, freeze-dried and stored in a $4{ }^{\circ} \mathrm{C}$ vacuum.

\subsection{In Vitro VEGF Release Profile}

The VEGF release profiles were assessed by soaking the scaffolds in $5 \mathrm{~mL}$ of $37^{\circ} \mathrm{C}$ Dulbecco's modified Eagle's medium (DMEM) for 14 days. The release of VEGF was determined using an enzyme-linked immunosorbent assay kit (Invitrogen, Thermo Fisher Scientific, Carlsbad, CA, USA) according to the manufacturer's instruction. The concentration was compared to a standard curve and a neat scaffold was used as control. A 96-well spectrophotometer (TECAN Infinite Pro M200, Männedorf, Switzerland) was used to measure for absorbances. All experiments were performed in triplicate.

\subsection{Cell Adhesion and Proliferation}

Prior to cell experiments, all 3D-printed scaffolds were disinfected by soaking them in $75 \%$ alcohol followed by $20 \mathrm{~min}$ of UV irradiation. HUVECs and hMSCs at a density of $5 \times 10^{4}$ cells $/ \mathrm{mL}$ were seeded onto the scaffold and cultured at various time-points. The PrestoBlue assay (Invitrogen, Carlsbad, CA, USA) was used to assess for cell viability at pre-determined time points. In brief, $30 \mu \mathrm{L}$ of PrestoBlue solution and $300 \mu \mathrm{L}$ of complete growth medium were added into each well and incubated for $30 \mathrm{~min}$. A volume of $100 \mu \mathrm{L}$ from each well was then transferred to a fresh 96-well ELISA plate and analyzed using a multi-well spectrophotometer at $570 \mathrm{~nm}$ with a $600 \mathrm{~nm}$ reference wavelength. Cells cultured on culture plates were used as controls $(\mathrm{Ctl})$. All experiments were performed in triplicate.

\subsection{Fluorescent Staining}

After different time-points of culture, the scaffolds were washed with phosphate-buffered saline (PBS) solution, fixed in 4\% paraformaldehyde (Sigma-Aldrich, St. Louis, MO, USA) for 15 min and then permeabilized with $0.1 \%$ Triton X-100 (Sigma-Aldrich) PBS solution for $15 \mathrm{~min}$ at room temperature. The F-actin filaments were then stained with Alexa Fluor 488 Phalloidin (1:300 dilution in PBS, Invitrogen) for $1 \mathrm{~h}$. The nuclei were stained with $300 \mathrm{nM}$ DAPI (Invitrogen) for $30 \mathrm{~min}$. After washing, the morphology was observed using a confocal laser scanning microscope (Leica TCS SP8, Wetzlar, Germany).

\subsection{Angiogenic and Osteogenic-Related Protein Secretion}

The cell was cultured on scaffolds with a commercial cell differentiation medium, such as osteogenic medium from StemPro ${ }^{\mathrm{TM}}$ (osteogenesis differentiation kit, Invitrogen), and the angiogenesis starter kit 
(Invitrogen), for 3 days, in order to assess the levels of alkaline phosphatase (ALP), osteopontin (OPN), osteocalcin (OC), von Willebrand Factor (vWF) and angiopoietin 1 (Ang-1) proteins with an ELISA kit (Invitrogen), according to the manufacturer's instructions. Protein concentrations were measured by correlation with a standard curve. All experiments were performed in triplicate.

\subsection{Alizarin Red S Staining}

hMSCs were cultured on the scaffolds with an osteogenic differentiation medium for 14 days. This was done in accordance with methods that were previously described [14]. alizarin red S staining was used to determine for calcium deposition. In brief, the specimens were fixed with $4 \%$ paraformaldehyde (Sigma-Aldrich) for $15 \mathrm{~min}$ and then incubated with $0.5 \%$ alizarin red S (Sigma-Aldrich) at a pH of 4.0 for $15 \mathrm{~min}$ at room temperature. The cells were then washed with PBS and photographed using a BX53 Olympus fluorescence microscope (Olympus, Tokyo, Japan) at $200 \times$ magnification. In addition, the alizarin red S solution was quantified by first adding $20 \%$ methanol and $10 \%$ acetic acid in water for $15 \mathrm{~min}$. The solution was then transferred to a 96-well plate and the absorbance of alizarin red $\mathrm{S}$ was determined using a spectrophotometer with a $450 \mathrm{~nm}$ wavelength.

\subsection{Rabbit Model of Femoral Bone Defects}

All the in vivo experimental protocols used in this study were approved by the Animal Experimental Ethics Committee of National Taiwan University. The New Zealand white male rabbits used in this study were 3 months old, with a weight of $1.8-2.0 \mathrm{~kg}$. We used a bone drill to remove bone and create critical-size defects in the femur which were $6 \mathrm{~mm}$ in diameter and $6 \mathrm{~mm}$ in depth. The scaffolds from the various groups in this study were then implanted at the sites of the critical lesions. The animal experiments were divided into four groups, namely HA, HA/VEGF, HACS and HACS/VEGF. The rabbits were anesthetized with chlorhexidine injections with continuous $5 \%$ isoflurane in $100 \%$ oxygen, using a gas anesthesia machine (Engler ADS1000, Hialeah, FL, USA). The hair on the hind legs was first shaved with an electric shaver and then disinfected with alcohol and iodine before the dissection of the skin. The muscle fascia was then dissected to expose the femur and special precautions were taken to avoid dissecting excess muscle or causing injury to nerve or blood vessels. The scaffold was then implanted into the defect site, and the wound was closed with sutures and covered with a thick layer of anti-inflammatory ointment. All rabbits fasted for 1 day prior to surgery.

\subsection{Microcomputed Tomography}

Images of all in vivo specimens were taken with a high $360^{\circ}$ spatial resolution microcomputed tomography ( $\mu \mathrm{CT}$, SkyScan 1076, SkyScan Inc., Kontich, Belgium) equipped with a 1.4 M X-ray CCD camera. The pre-determined settings were set at: maximum tube current of $0.2 \mathrm{~mA}$, maximum tube voltage of $160 \mathrm{kV}$, and a $1 \mathrm{~mm}$ focus size. For each sample image, a 70-V tube voltage and 70-A current were maintained in the X-ray tube. For the femur scans, slice increments of $30 \mathrm{~mm}$ with a total of 400 images were taken. The slices were then analyzed using 3Di-Cat for thresholding to create 3D models for further assessment and quantitative histomorphometric analysis. SkyScan software was used to recognize new bony tissues and to analyze the bone volume per tissue volume (BV/TV) and trabecular thickness (Tb.Th) in the specimens.

\subsection{Histological Staining}

After 8 weeks of culture, the retrieved in vivo samples were fixed in $10 \%$ formalin for $48 \mathrm{~h}$, rinsed several times with PBS, embedded in an optimum cutting temperature compound $\left(\mathrm{OCT}^{\circledR}\right)$ (KMA-0100-00A, CellPath Ltd., Newtown, Wales, UK) and sectioned into slices, with 6 mm intervals in between. Longitudinal $6 \mu \mathrm{m}$ sections were then prepared from each slice using a sawing microtome technique. The sections were then stained with hematoxylin and eosin (H\&E) using a modified Masson's trichrome stain kit (ScyTek Lab., West Logan, UT, USA) and a von Kossa kit (ScyTek), 
according to manufacturers' instructions. Collagen was stained blue by trichrome staining while calcified bone was stained red by von Kossa staining, which allowed us to differentiate between the osteoid and calcified tissues. The sections were examined using the BX53 Olympus fluorescence microscope at $50 \times$ magnification.

\subsection{Statistical Analyses}

The one-way analysis of variance (ANOVA) was used to determine any statistically significant differences between the means of the experimental groups. Scheffé's method was used to account for multiple comparisons amongst the group means. All data were considered to be statistically significant with a $p$-value of $<0.05$.

\section{Conclusions}

In conclusion, the evidence of the in vitro experiments conducted in the present study suggests that HACS/VEGF scaffolds had good degradation and mechanical strength and were able to enhance ALP, OC, vWF and Ang-1 expression in a time-dependent manner. Furthermore, the evidence of the in vivo results showed that HACS/VEGF had excellent osteoinduction and osteogenesis abilities in rat femur defect models. This article provides an insight into the growth factors derived from the scaffold, which modified cell ability and promoted bone regeneration in the bone defect.

Author Contributions: Data Curation, C.-Y.C. and C.-L.Y.; Formal Analysis, C.-C.C.; Funding Acquisition, C.-P.L.; Investigation, C.-C.C. and A.K.-X.L.; Methodology, C.-C.C. and A.K.-X.L.; Writing-Original Draft, C.-Y.C. and C.-Y.W. and A.K.-X.L.; Writing-Review and Editing, C.-P.L. All authors have read and agreed to the published version of the manuscript.

Funding: This work was financially supported by the "Advanced Research Center for Green Materials Science and Technology" from The Featured Area Research Center Program within the framework of the Higher Education Sprout Project by the Ministry of Education (109L9006) and the Ministry of Science and Technology in Taiwan (MOST 109-2634-F-002-042, 108-2314-B-002-044 and 106-2314-B-002 -038 -MY3).

Conflicts of Interest: The authors declare no conflict of interest.

\section{References}

1. Wang, W.C.; Nune, K.C.; Tan, L.; Zhang, N.; Dong, J.; Yan, J.; Misra RD, K.; Yang, K. Bone regeneration of hollow tubular magnesium-strontium scaffolds in critical-size segmental defects: Effect of surface coatings. Mater. Sci. Eng. C Mater. Biol. Appl. 2019, 100, 297-307. [CrossRef]

2. He, D.; Dong, W.; Tang, S.; Wei, J.; Liu, Z.; Gu, X.; Li, M.; Guo, H.; Niu, Y. Tissue engineering scaffolds of mesoporous magnesium silicate and $\operatorname{poly}(\varepsilon$-caprolactone)-poly(ethylene glycol)-poly( $\varepsilon$-caprolactone) composite. J. Mater. Sci. Mater. Med. 2014, 25, 1415-1424. [CrossRef] [PubMed]

3. He, J.; Chen, G.; Liu, M.; Xu, Z.; Chen, H.; Yang, L.; Lv, Y. Scaffold strategies for modulating immune microenvironment during bone regeneration. Mater. Sci. Eng. C Mater. Biol. Appl. 2020, 108, 110411. [CrossRef]

4. Jha, P.; Danewalia, S.S.; Sharma, G.; Singh, K. Antimicrobial and bioactive phosphate-free glass-ceramics for bone tissue engineering applications. Mater. Sci. Eng. C Mater. Biol. Appl. 2018, 86, 9-17. [CrossRef] [PubMed]

5. Hong, S.; Kang, E.Y.; Byeon, J.; Jung, S.H.; Hwang, C. Embossed membranes with vascular patterns guide vascularization in a 3D tissue model. Polymers 2019, 11, 792. [CrossRef] [PubMed]

6. Wu, Y.H.; Chiu, Y.C.; Lin, Y.H.; Ho, C.C.; Shie, M.Y.; Chen, Y.W. 3D-printed bioactive calcium

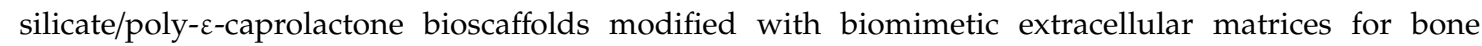
regeneration. Int. J. Mol. Sci. 2019, 20, 942. [CrossRef]

7. Chen, M.; Zhao, F.; Li, Y.; Wang, M.; Chen, X.; Lei, B. 3D-printed photoluminescent bioactive scaffolds with biomimetic elastomeric surface for enhanced bone tissue engineering. Mater. Sci. Eng. C Mater. Biol. Appl. 2020, 106, 110153. [CrossRef] 
8. Du, X.; Wei, D.; Huang, L.; Zhu, M.; Zhang, Y.; Zhu, Y. 3D printing of mesoporous bioactive glass/silk fibroin composite scaffolds for bone tissue engineering. Mater. Sci. Eng. C Mater. Biol. Appl. 2019, 103, 109731. [CrossRef]

9. Anada, T.; Pan, C.C.; Stahl, A.M.; Mori, S.; Fukuda, J.; Suzuki, O.; Yang, Y. Vascularized bone-mimetic hydrogel constructs by 3D bioprinting to promote osteogenesis and angiogenesis. Int. J. Mol. Sci. 2019, 20, 1096. [CrossRef]

10. Shie, M.Y.; Shen, Y.F.; Astuti, S.D.; Lee, K.X.; Lin, S.H.; Dwijaksara NL, B.; Chen, Y.W. Review of polymeric materials in 4D printing biomedical applications. Polymers 2019, 11, 1864. [CrossRef]

11. Lin, Y.H.; Chuang, T.Y.; Chiang, W.H.; Chen IW, P.; Wang, K.; Shie, M.Y.; Chen, Y.W. The synergistic effects of graphene-contained 3D-printed calcium silicate/poly- $\varepsilon$-caprolactone scaffolds promote FGFR-induced osteogenic/angiogenic differentiation of mesenchymal stem cells. Mater. Sci. Eng. C Mater. Biol. Appl. 2019, 104, 109887. [CrossRef] [PubMed]

12. Tsai, C.H.; Hung, C.H.; Kuo, C.N.; Chen, C.Y.; Peng, Y.N.; Shie, M.Y. Improved bioactivity of 3D printed porous titanium alloy scaffold with chitosan/magnesium-calcium silicate composite for orthopaedic applications. Materials 2019, 12, 203. [CrossRef] [PubMed]

13. Chu, L.; Jiang, G.; Hu, X.L.; James, T.D.; He, X.P.; Li, Y.; Tang, T. Biodegradable macroporous scaffold with nano-crystal surface microstructure for highly effective osteogenesis and vascularization. J. Mater. Chem. B 2018, 6, 1658-1667. [CrossRef] [PubMed]

14. Yu, C.T.; Wang, F.M.; Liu, Y.T.; Ng, H.Y.; Jhong, Y.R.; Hung, C.H.; Chen, Y.W. Effect of bone morphogenic protein-2 loaded mesoporous strontium substitution calcium silicate/recycled fish gelatin 3D cell-laden scaffold for bone tissue engineering. Processes 2020, 8, 493. [CrossRef]

15. Chen, Y.W.; Shen, Y.F.; Ho, C.C.; Yu, J.; Wu, Y.H.; Wang, K.; Shih, C.T.; Shie, M.Y. Osteogenic and angiogenic potentials of the cell-laden hydrogel/mussel-inspired calcium silicate complex hierarchical porous scaffold fabricated by 3D bioprinting. Mater. Sci. Eng. C Mater. Biol. Appl. 2018, 91, 679-687. [CrossRef]

16. Chiu, Y.C.; Shie, M.Y.; Lin, Y.H.; Lee, K.X.; Chen, Y.W. Effect of strontium substitution on the physicochemical properties and bone regeneration potential of 3D printed calcium silicate scaffolds. Int. J. Mol. Sci. 2019, 20, 2729. [CrossRef]

17. Kao, C.T.; Chen, Y.J.; Ng, H.Y.; Lee, K.X.; Huang, T.H.; Lin, T.F.; Hsu, T.T. Surface modification of calcium silicate via mussel-inspired polydopamine and effective adsorption of extracellular matrix to promote osteogenesis differentiation for bone tissue engineering. Materials 2018, 11, 1664. [CrossRef]

18. Chang, C.H.; Lin, C.Y.; Liu, F.H.; Chen, H.C.; Lin, C.P.; Ho, H.N.; Liao, Y.S. 3D printing bioceramic porous scaffolds with good mechanical property and cell affinity. PLoS ONE 2015, 10, e0143713. [CrossRef]

19. Martin, V.; Ribeiro, I.A.; Alves, M.M.; Gonçalves, L.; Claudio, R.A.; Grenho, L.; Fernandes, M.H.; Gomes, P.; Santos, C.F.; Bettencourt, A.F. Engineering a multifunctional 3D-printed PLA-collagen-minocycline-nanoHydroxyapatite scaffold with combined antimicrobial and osteogenic effects for bone regeneration. Mater. Sci. Eng. C Mater. Biol. Appl. 2019, 101, 15-26. [CrossRef]

20. Salama, A. Cellulose/calcium phosphate hybrids: New materials for biomedical and environmental applications. Int. J. Biol. Macromol. 2019, 127, 606-617. [CrossRef]

21. Meskinfam, M.; Bertoldi, S.; Albanese, N.; Cerri, A.; Tanzi, M.C.; Imani, R.; Baheiraei, N.; Farokhi, M.; Farè, S. Polyurethane foam/nano hydroxyapatite composite as a suitable scaffold for bone tissue regeneration. Mater. Sci. Eng. C Mater. Biol. Appl. 2018, 82, 130-140. [CrossRef] [PubMed]

22. Fathi, M.H.; Hanifi, A.; Mortazavi, V. Preparation and bioactivity evaluation of bone-like hydroxyapatite nanopowder. J. Mater. Process Technol. 2008, 202, 536-542. [CrossRef]

23. Zhou, H.; Lee, J. Nanoscale hydroxyapatite particles for bone tissue engineering. Acta Biomater. 2011, 7, 2769-2781. [CrossRef] [PubMed]

24. Chang, K.C.; Chang, C.C.; Chen, W.T.; Hsu, C.K.; Lin, F.H.; Lin, C.P. Development of calcium phosphate/sulfate biphasic cement for vital pulp therapy. Dent. Mater. 2014, 30, e362-e370. [CrossRef]

25. Hao, F.; Qin, L.; Liu, J.; Chang, J.; Huan, Z.; Wu, L. Assessment of calcium sulfate hemihydrate-tricalcium silicate composite for bone healing in a rabbit femoral condyle model. Mater. Sci. Eng. C Mater. Biol. Appl. 2018, 88, 53-60. [CrossRef]

26. Chiang, Y.C.; Chang, H.H.; Wong, C.C.; Wang, Y.P.; Wang, Y.H.; Huang, W.H.; Lin, C.P. Nanocrystalline calcium sulfate/hydroxyapatite biphasic compound as a TGF- $\beta 1 /$ VEGF reservoir for vital pulp therapy. Dent. Mater. 2016, 32, 1197-1208. [CrossRef] [PubMed] 
27. Aksel, H.; Öztürk, Ş.; Serper, A.; Ulubayram, K. VEGF/BMP-2 loaded three-dimensional model for enhanced angiogenic and odontogenic potential of dental pulp stem cells. Int. Endod. J. 2018, 51, 420-430. [CrossRef] [PubMed]

28. Xia, B.; Lv, Y. Dual-delivery of VEGF and NGF by emulsion electrospun nanofibrous scaffold for peripheral nerve regeneration. Mater. Sci. Eng. C Mater. Biol. Appl. 2018, 82, 253-264. [CrossRef]

29. Raftery, R.M.; Mencía Castaño, I.; Chen, G.; Cavanagh, B.; Quinn, B.; Curtin, C.M.; Cryan, S.A.; O’Brien, F.J. Translating the role of osteogenic-angiogenic coupling in bone formation: Highly efficient chitosan-pDNA activated scaffolds can accelerate bone regeneration in critical-sized bone defects. Biomaterials 2017, 149, 116-127. [CrossRef]

30. Casarrubios, L.; Gómez-Cerezo, N.; Sánchez-Salcedo, S.; Feito, M.J.; Serrano, M.C.; Saiz-Pardo, M.; Ortega, L.; de Pablo, D.; Díaz-Güemes, I.; Fernández-Tomé, B.; et al. Silicon substituted hydroxyapatite/VEGF scaffolds stimulate bone regeneration in osteoporotic sheep. Acta Biomater. 2019, 101, 544-553. [CrossRef]

31. Li, H.; Jiang, F.; Ye, S.; Wu, Y.; Zhu, K.; Wang, D. Bioactive apatite incorporated alginate microspheres with sustained drug-delivery for bone regeneration application. Mater. Sci. Eng. C Mater. Biol. Appl. 2016, 62, 779-786. [CrossRef]

32. Kuo, T.F.; Lee, S.Y.; Wu, H.D.; Poma, M.; Wu, Y.W.; Yang, J.C. An in vivo swine study for xeno-grafts of calcium sulfate-based bone grafts with human dental pulp stem cells (hDPSCs). Mater. Sci. Eng. C Mater. Biol. Appl. 2015, 50, 19-23. [CrossRef] [PubMed]

33. Subramaniam, S.; Fang, Y.H.; Sivasubramanian, S.; Lin, F.H.; Lin, C.P. Hydroxyapatite-calcium sulfate-hyaluronic acid composite encapsulated with collagenase as bone substitute for alveolar bone regeneration. Biomaterials 2015, 74, 99-108. [CrossRef] [PubMed]

34. Varoni, E.M.; Altomare, L.; Cochis, A.; GhalayaniEsfahani, A.; Cigada, A.; Rimondini, L.; De Nardo, L. Hierarchic micro-patterned porous scaffolds via electrochemical replica-deposition enhance neo-vascularization. Biomed. Mater. 2016, 11, 025018. [CrossRef] [PubMed]

35. Lin, Y.H.; Chiu, Y.C.; Shen, Y.F.; Wu, Y.H.; Shie, M.Y. Bioactive calcium silicate/poly- $\varepsilon$-caprolactone composite scaffolds 3D printed under mild conditions for bone tissue engineering. J. Mater. Sci. Mater. Med. 2018, 29, 11. [CrossRef] [PubMed]

36. Huang, K.H.; Chen, Y.W.; Wang, C.Y.; Lin, Y.H.; Wu, Y.H.; Shie, M.Y.; Lin, C.P. Enhanced capability of BMP-2-loaded mesoporous calcium silicate scaffolds to induce odontogenic differentiation of human dental pulp cells. J. Endod. 2018, 44,1677-1685. [CrossRef]

37. Prasadh, S.; Suresh, S.; Wong, R. Osteogenic potential of graphene in bone tissue engineering scaffolds. Materials 2018, 11, 1430. [CrossRef]

38. Huang, K.H.; Lin, Y.H.; Shie, M.Y.; Lin, C.P. Effects of bone morphogenic protein-2 loaded on the 3D-printed MesoCS scaffolds. J. Formos. Med. Assoc. 2018, 117, 879-887. [CrossRef]

39. Lalzawmliana, V.; Anand, A.; Roy, M.; Kundu, B.; Nandi, S.K. Mesoporous bioactive glasses for bone healing and biomolecules delivery. Mater. Sci. Eng. C Mater. Biol. Appl. 2020, 106, 110180. [CrossRef]

40. Jahangir, S.; Hosseini, S.; Mostafaei, F.; Sayahpour, F.A.; Eslaminejad, M.B. 3D-porous $\beta$-tricalcium phosphate-alginate-gelatin scaffold with DMOG delivery promotes angiogenesis and bone formation in rat calvarial defects. J. Mater. Sci. Mater. Med. 2018, 30, 1. [CrossRef]

41. Yusop, A.H.; Sarian, M.N.; Januddi, F.S.; Ahmed, Q.U.; Kadir, M.R.; Hartanto, D.; Hermawan, H.; Nur, H. Structure, degradation, drug release and mechanical properties relationships of iron-based drug eluting scaffolds: The effects of PLGA. Mater. Des. 2018, 160, 203-217. [CrossRef]

42. Clarkin, C.E.; Emery, R.J.; Pitsillides, A.A.; Wheeler-Jones CP, D. Evaluation of VEGF-mediated signaling in primary human cells reveals a paracrine action for VEGF in osteoblast-mediated crosstalk to endothelial cells. J. Cell. Physiol. 2008, 214, 537-544. [CrossRef] [PubMed]

43. Bragdon, B.; Moseychuk, O.; Saldanha, S.; King, D.; Julian, J.; Nohe, A. Bone morphogenetic proteins: A critical review. Cell. Signal. 2011, 23, 609-620. [CrossRef]

44. Cho, Y.D.; Yoon, W.J.; Woo, K.M.; Baek, J.H.; Park, J.C.; Ryoo, H.M. The canonical BMP signaling pathway plays a crucial part in stimulation of dentin sialophosphoprotein expression by BMP-2. J. Biol. Chem. 2010, 285, 36369-36376. [CrossRef]

45. Jeon, O.H.; Panicker, L.M.; Lu, Q.; Chae, J.J.; Feldman, R.A.; Elisseeff, J.H. Human iPSC-derived osteoblasts and osteoclasts together promote bone regeneration in 3D biomaterials. Sci. Rep. 2016, 6, 26761. [CrossRef] 
46. Chen, L.; Deng, C.; Li, J.; Yao, Q.; Chang, J.; Wang, L.; Wu, C. 3D printing of a lithium-calcium-silicate crystal bioscaffold with dual bioactivities for osteochondral interface reconstruction. Biomaterials 2019, 196, 138-150. [CrossRef]

47. Li, Z.; Mi, W.; Wang, H.; Su, Y.; He, C. Nano-hydroxyapatite/polyacrylamide composite hydrogels with high mechanical strengths and cell adhesion properties. Colloids Surf. B 2014, 123, 959-964. [CrossRef]

48. Wu, X.; Bruschi, M.; Waag, T.; Schweeberg, S.; Tian, Y.; Meinhardt, T.; Stigler, R.; Larsson, K.; Funk, M.; Steinmüller Nethl, D.; et al. Functionalization of bone implants with nanodiamond particles and angiopoietin-1 to improve vascularization and bone regeneration. J. Mater. Chem. B 2017, 5, 6629-6636. [CrossRef]

49. Yodthong, T.; Kedjarune-Leggat, U.; Smythe, C.; Wititsuwannakul, R.; Pitakpornpreecha, T. 1-Quebrachitol promotes the proliferation, differentiation, and mineralization of MC3T3-E1 cells: Involvement of the BMP-2/Runx2/MAPK/Wnt/ $\beta$-catenin signaling pathway. Molecules 2018, 23, 3086. [CrossRef] [PubMed]

50. Choi, H.; Jeong, B.C.; Hur, S.W.; Kim, J.W.; Lee, K.B.; Koh, J.T. The angiopoietin-1 variant COMP-ang1 enhances BMP2-induced bone regeneration with recruiting pericytes in critical sized calvarial defects. PLoS ONE 2015, 10, 0140502. [CrossRef]

51. Liu, Y.; Ding, C.; He, L.; Yang, X.; Gou, Y.; Xu, X.; Liu, Y.; Zhao, C.; Li, J.; Li, J. Bioinspired heptapeptides as functionalized mineralization inducers with enhanced hydroxyapatite affinity. J. Mater. Chem. B 2018, 6, 1984-1994. [CrossRef]

52. Chen, S.; Shi, Y.; Zhang, X.; Ma, J. Evaluation of BMP-2 and VEGF loaded 3D printed hydroxyapatite composite scaffolds with enhanced osteogenic capacity in vitro and in vivo. Mater. Sci. Eng. C Mater. Biol. Appl. 2020, 112, 110893. [CrossRef] [PubMed]

53. Cheng, C.H.; Chen, Y.W.; Lee, K.X.; Yao, C.H.; Shie, M.Y. Development of mussel-inspired 3D-printed poly (lactic acid) scaffold grafted with bone morphogenetic protein-2 for stimulating osteogenesis. J. Mater. Sci. Mater. Med. 2019, 30, 78. [CrossRef] [PubMed]

54. Tcacencu, I.; Rodrigues, N.; Alharbi, N.; Benning, M.; Toumpaniari, S.; Mancuso, E.; Marshall, M.; Bretcanu, O.; Birch, M.; McCaskie, A.; et al. Osseointegration of porous apatite-wollastonite and poly(lactic acid) composite structures created using 3D printing techniques. Mater. Sci. Eng. C Mater. Biol. Appl. 2018, 90, 1-7. [CrossRef] [PubMed]

55. Akkineni, A.R.; Luo, Y.; Schumacher, M.; Nies, B.; Lode, A.; Gelinsky, M. 3D plotting of growth factor loaded calcium phosphate cement scaffolds. Acta Biomater. 2015, 27, 264-274. [CrossRef] [PubMed] 